\title{
Cardiac Differentiation of Pluripotent Stem Cells
}

\author{
Kristiina Rajala, ${ }^{1}$ Mari Pekkanen-Mattila, ${ }^{1}$ and Katriina Aalto-Setälä ${ }^{1,2}$ \\ ${ }^{1}$ Regea - Institute for Regenerative Medicine, University of Tampere, Tampere University Hospital, 33520 Tampere, Finland \\ ${ }^{2}$ Heart Center, Tampere University Hospital, 33520 Tampere, Finland
}

Correspondence should be addressed to Kristiina Rajala, kristiina.m.rajala@regea.fi

Received 16 November 2010; Revised 1 February 2011; Accepted 8 February 2011

Academic Editor: Steve Oh

Copyright (C) 2011 Kristiina Rajala et al. This is an open access article distributed under the Creative Commons Attribution License, which permits unrestricted use, distribution, and reproduction in any medium, provided the original work is properly cited.

\begin{abstract}
The ability of human pluripotent stem cells to differentiate towards the cardiac lineage has attracted significant interest, initially with a strong focus on regenerative medicine. The ultimate goal to repair the heart by cardiomyocyte replacement has, however, proven challenging. Human cardiac differentiation has been difficult to control, but methods are improving, and the process, to a certain extent, can be manipulated and directed. The stem cell-derived cardiomyocytes described to date exhibit rather immature functional and structural characteristics compared to adult cardiomyocytes. Thus, a future challenge will be to develop strategies to reach a higher degree of cardiomyocyte maturation in vitro, to isolate cardiomyocytes from the heterogeneous pool of differentiating cells, as well as to guide the differentiation into the desired subtype, that is, ventricular, atrial, and pacemaker cells. In this paper, we will discuss the strategies for the generation of cardiomyocytes from pluripotent stem cells and their characteristics, as well as highlight some applications for the cells.
\end{abstract}

\section{Introduction}

Human cardiomyocytes can be isolated from heart biopsies, but the access to human heart tissue is very limited, and the procedure is complicated; it is difficult to obtain viable cell preparations in large quantities, and the cells obtained do not beat spontaneously. Thus, physiologically relevant in vitro models for human cardiomyocytes are currently limited. This has led in the creation of alternative models, such as isolation of cardiomyocytes from various newborn animals or production of genetically engineered cell lines overexpressing certain target proteins (e.g., ion channels) [1]. All of these models, however, share significant limitations with respect to their basic physiological differences compared to human cardiomyocytes as well as high costs and ethical questions. A number of different human tissues have been proposed as the source of stem cells able to generate new cardiomyocytes (e.g., fetal cardiomyocytes, adult cardiac progenitor cells, skeletal myoblasts, bone marrow-derived stem cells, adipose-derived stem cells, umbilical cord-derived stem cells, and pluripotent stem cells) [2]. The cardiac differentiation potential of adult, multipotent, stem cells found in fetal and adult tissues, however, is controversial
$[3,4]$. This has been attributed to the limited plasticity of adult stem cells, which precludes their differentiation into functional cardiomyocytes. The only adult stem cells that clearly have the potential to differentiate into beating cardiomyocytes are cardiac progenitor cells [5]. In addition, so far, only pluripotent stem cells have been shown in vitro to efficiently differentiate into spontaneously contracting cardiomyocyte-like cells [6-9].

Pluripotent stem cells have nearly unlimited self-renewal capability in vitro and have the ability to differentiate into all three germ layers and thus, in principle, can give rise to all cell types of the human body [10]. Since the first description of the isolation and characterization of human embryonic stem cells (hESCs) from donor blastocysts [11], there have been reports of differentiation of hESCs to functional cardiomyocytes by multiple differentiation methods. Recent breakthroughs in the field of induced pluripotent stem (iPS) cell technology have demonstrated that human iPS cells may provide an additional source for in vitro differentiated cardiomyocytes, sharing similarities with their hESC-derived counterparts [12-14]. Currently, cardiomyocytes can be differentiated from pluripotent stem cells by (1) spontaneous embryoid body (EB) differentiation 
in suspension, (2) coculture with mouse endoderm-like cells (END-2 cells), or (3) guiding the cardiac differentiation with defined growth factors either in suspension or in monolayer culture [15].

Owing to the cardiac phenotype and the functional properties of the pluripotent stem cell-derived cardiomyocytes, they can offer more physiologically and clinically relevant reproducible human cell models than presently available. In vitro differentiated cardiomyocytes may serve as models to study early events of human cardiogenesis and have the potential to be used in pharmaceutical drug discovery and safety toxicology. Animal models currently widely used in drug metabolism and toxicity studies are not fully reliable predictors of human responses because of basic physiological differences between species such as remarkably faster beating rate of the mouse may override the effects of arrhythmias which would be severe for human. It is anticipated that pluripotent stem cell-derived cardiomyocytes will be important in vitro tools for drug safety test which may drastically facilitate drug development and generation of safer drugs. In the field of cardiac regenerative repair, stem cell-derived cardiomyocytes would facilitate the discovery of small molecules promoting cardiomyocyte differentiation to be used for the activation of endogenous cardiac stem cells in clinical settings [15]. There is an urgent need to standardize and validate assays involving pluripotent stem cell-derived cardiomyocytes as well as to compare these cardiomyocytes with established in vitro and in vivo models in order to effectively determine the capabilities and limitations of the new models in making accurate predictions of the cardiac safety profile of new potential drugs during the development $[15,16]$. The ability to reprogram adult cells to pluripotent stem cells and to genetically manipulate stem cells presents opportunities to develop models of human diseases $[17,18]$. Until today, many severe diseases have been studied in animal models, particularly using transgenic mice. Although mouse models can provide valuable information, differences between human and mouse physiology limit the applicability of the results. iPS cells derived from patients suffering from various cardiac diseases or disorders, such as channelopathies or congenital heart disease $[19,20]$, are anticipated to become important tools for studying the mechanisms underlaying the disease pathogenesis and investigations of new treatment opportunities. However, it remains to be demonstrated that in vitro generated patientspecific iPS cell-derived cardiomyocytes actually recapitulate the appropriate disease phenotype observed in the adult heart.

Adult human cardiomyocytes are considered terminally differentiated cells. Although a small percentage of the cardiomyocytes may have proliferation capacity, it is not sufficient to replace injured or dead cardiomyocytes, for example, following myocardial injury. In recent years, the stem cell technology has raised hopes for new treatments for cardiac tissue damage with limited regenerative capacity. The possibility to apply pluripotent stem cell-derived cardiomyocytes to repair damaged myocardium has been demonstrated in preclinical studies to be a feasible approach although many hurdles remain to be solved before these developments can be translated to the clinic [21-28]. In brief, the obstacles to be solved include the generation of purified cell preparations that eliminate the risk of teratoma formation, defining the optimal timing for cell transplantation after myocardial infarction, the appropriate level of maturation of the cell preparation, dose and mechanism of delivery to facilitate successful engraftment, minimizing graft cell death following transplantation, and avoiding immune rejection of the graft [16]. Additionally, concerns remain that currently available pluripotent stem cell-derived cardiomyocyte preparations include myocytes with nodal, atrial, and ventricular type of action potential (AP) properties $[8,9]$. This electrophysiological heterogeneity represents both an opportunity and a challenge to the application of stem cell-derived cardiomyocytes to cardiac repair. An enriched preparation of nodal cells would be of potential use in the formation of a biological pacemaker [29]. On the other hand, nodal cells would be needed to exclude from cardiomyocyte preparations for infarct repair, as their sustained pacemaking activity and unique neurohormonal responsivity could exacerbate the already elevated risk of arrhythmias [30].

Efficient methods to induce differentiation to cardiomyocytes that generate homogenous populations of cardiomyocytes of adequate quality, reproducibly, and in large quantities are a prerequisite for any of these applications. Future cell therapies will also require defined cardiomyocyte production protocols fulfilling the regulatory requirements. In this paper, we describe the developmental progression from a pluripotent stem cell state to cardiomyocyte and provide an overview of protocols for cardiac differentiation of pluripotent stem cells as well as enrichment strategies of cardiomyocytes so far available.

\section{Lessons from Heart Development}

The earliest events of organogenesis during embryonic development are the formation of the heart. Although the knowledge regarding the molecular mechanisms that govern cardiogenesis in humans is still in its infancy, experimental animal models have been of great value for identifying various molecular events and a number of key regulators operating under the different stages of the early cell commitment process during cardiogenesis. Studies in mice and chick embryos have demonstrated that the heart tissue is composed of three major mesoderm-derived cell lineages: the cardiac myocyte, the vascular smooth muscle, and the endothelial cell lineages. Soon after gastrulation, a few days after fertilization, the three embryonic layers form, the endoderm, the ectoderm, and the mesoderm. The primitive streak is formed from primitive endoderm and is the origin of many tissues. Cardiac progenitors form in the posterior primitive streak [31]. Four main steps are required to generate cardiomyocytes from pluripotent stem cells: (1) formation of mesoderm, (2) the patterning of mesoderm toward anterior mesoderm or cardiogenic mesoderm, (3) formation of cardiac mesoderm, and (4) maturation of early cardiomyocytes. The induction of pluripotent stem 


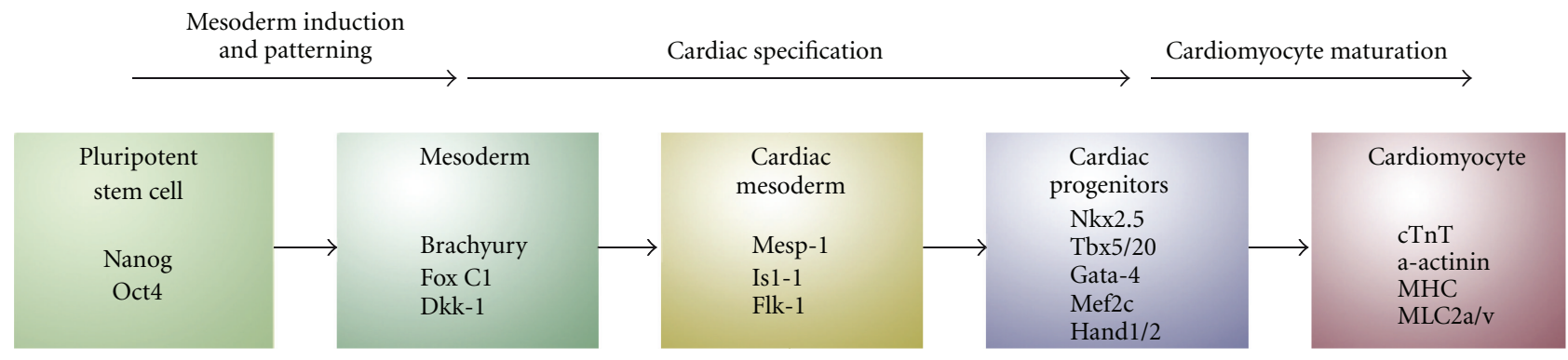

FIGURE 1: Diagram depicting sequential steps required for obtaining cardiomyocytes from pluripotent stem cells. Early mesoderm differentiates via cardiac mesoderm and committed cardiac progenitors further to functional beating cardiomyocytes. Typical markers for each step are indicated.

cell differentiation to cardiac fate following these steps can be characterized by the expression of transcription factors, such as T/Brachyury for primitive streak mesoderm, Mesp1 for cardiogenic mesoderm, and Nkx2.5, Tbx $5 / 20$, Gata4, Mef2c, and Hand1/2 for cardiac mesoderm [32-36]. Mesp-1 is thought to induce an epithelial-mesenchyme transition in the epiblast and to bind directly to regulatory DNA sequences in the promoters of many members of the core cardiac regulatory network, including Nkx2.5 thereby promoting development of mesoderm precursors of the cardiovascular lineage as well as repressing the expression of key genes regulating other early mesoderm derivatives $[37,38]$. Maturing cardiomyocytes can be identified by the expression of cardiac structural proteins such as $\alpha$-actinin, $\alpha$-myosin heavy chain ( $\alpha$-MHC), or the cardiac isoform of Troponin-T (cTnT). By initiating the complex myocardial cross-regulatory network, these factors are believed to be involved in morphogenic events leading to the formation of the heart. Figure 1 illustrates various steps in the differentiation of pluripotent stem cells to cardiomyocytes and indicates the possible cell populations that may be available for isolation and expansion.

Cardiac development is a dynamic process that is tightly orchestrated by the sequential expression of multiple signal transduction proteins and transcription factors working in a combinatory manner. A number of signaling pathways and growth factors have been implicated in the development of specialized cardiac subtypes, and among the most studied are Wnts/Nodal, BMPs, and FGFs [39-42]. Since these factors work optimally during certain time window and, in some instances, antagonize cardiogenesis during other windows, the timing of the addition to guide the pluripotent stem cells in the desired differentiation direction must be carefully optimized.

In addition, microRNAs (mir) have been recently identified as major contributors to the differentiation process $[43,44]$. MicroRNAs are 22-23 nt long ssRNA involved in gene regulation and capable of inhibiting initiation of translation and inducing mRNA degradation. The heart expresses miR-1, miR-133, miR-206, and specifically miR208 [45, 46]. Furthermore, miR-143 and -145 also appear important for cardiomyogenesis [47]. A recent study investi- gated expression of miR-1 and miR-133 in mESCs and hESCs and compared their potential to induce Nkx2.5 in embryoid bodies and their influence on mesodermal differentiation. miR-1 increased the proportion of beating aggregates and thus appears to greatly enhance cardiac phenotype. On the contrary, miR-133 promotes also early mesoderm differentiation but inhibits further cardiac commitment [48]. Interestingly, both of these miRs are coexpressed from the same cluster [49]. Identification of miRs regulating the cardiac differentiation will offer another route for guiding the differentiation of cardiomyocytes.

The first step (i.e., mesoderm induction) in cardiac differentiation from pluripotent stem cells has been well characterized. Numerous studies have demonstrated that Wnts, BMPs, and transforming growth factor (TGF) $\beta$ family member Nodal (or Activin A as a substitute of Nodal) efficiently induce mesoderm $[50,51]$. Although some of the mechanisms that control for the next two steps in cardiac differentiation (i.e., patterning to cardiogenic mesoderm and the formation of cardiac mesoderm) have been characterized in experimental animal embryos, knowledge about how these mechanisms might be applied to pluripotent stem cell cardiogenesis is still lacking. Nodal and Wnt inhibition have been found to regulate the formation of cardiomyocytes in xenopus and chick embryos [52-54] and seem to be important for mouse ESC differentiation to cardiomyocytes $[55,56]$. Dickkopf-1 (Dkk-1) is often employed as a Wnt antagonist at this stage of differentiation protocols [57]. Another important signaling pathway is mediated by the transmembrane receptor Notch, which has been shown to induce the expression of a combination of the growth factors Wnt5a, BMP6, and Sfrp1, which increase the amount of cardiac progenitors form an ESC-derived mesoderm subpopulation [58]. The last step in the differentiation stages to cardiomyocytes is the differentiation of committed cardiac progenitors to beating cardiomyocytes, a process that often occurs spontaneously in vitro and is poorly understood but might be controlled by factors such as Wnt11 [56]. Taken together, very little is known about the two crucial steps in cardiogenesis from pluripotent stem cells that is, promotion of mesendoderm to form committed cardiac mesoderm and factors to give rise to cardiomyocytes. 
TABLE 1: Summary of prevalent cardiac differentiation methods.

\begin{tabular}{lccc}
\hline Method description & $\begin{array}{c}\text { Differentiation } \\
\text { efficiency } \%\end{array}$ & Stem cell type & Reference \\
\hline $\begin{array}{l}\text { Spontaneous embryoid body method } \\
\text { END-2 method }\end{array}$ & $<10 \%$ & hESC & Kehat et al. [6] \\
hiPSC & Zhang et al. [12] \\
$\begin{array}{l}\text { Guided differentiation method } \\
\text { Activin A, BMP4 }\end{array}$ & $20 \%-25 \%$ & hiPSC & Passier et al. [68], Graichen et al. [71] \\
$\begin{array}{l}\text { Guided differentiation method } \\
\text { Activin A, BMP4, bFGF, VEGF, Dkk-1 }\end{array}$ & $>30 \%$ & hESC & Freund et al. [70] \\
\end{tabular}

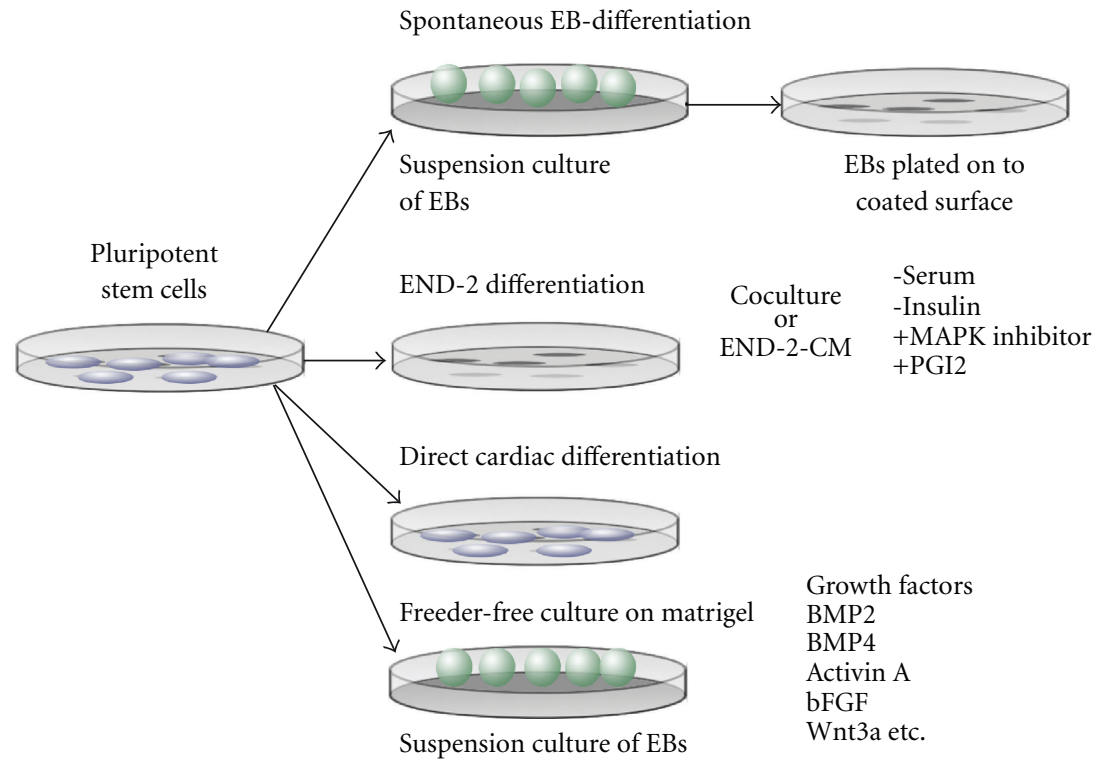

FIGURE 2: Schematic overview outlining differentiation approaches currently used for cardiomyocyte differentiation from pluripotent stem cells. The embryoid body approach has, thus far, been the most utilized way to obtain beating cardiomyocytes from pluripotent stem cells and the formation of three-dimensional cell aggregates initiates and facilitates the differentiation process. Generally, cells are transferred to suspension cultures, or in order to obtain more stable and reproducible cell aggregates, the embryoid bodies are formed using the hanging-drop or the forced aggregation method. Using the END-2 approach, cardiomyocyte differentiation is triggered either by coculture of pluripotent stem cells, with END-2 cells or by embryoid body formation in suspension culture using END-2 conditioned medium. The depletion of serum and insulin has been shown to facilitate cardiogenesis in this approach, and it can be further enhanced by inhibiting p38 MAPK pathway by a specific inhibitor or by adding prostaglandin $\mathrm{I}_{2}$. In the guided differentiation approach, undifferentiated pluripotent stem cells are cultured under feeder cell-free conditions or in suspension culture after embryoid body formation. Cardiac differentiation is induced with various growth factors, such as BMP2, BMP4, Activin A, bFGF, and Wnt3a.

\section{Cardiac Differentiation of Pluripotent Stem Cells}

Table 1 and Figure 2 summarizes the differentiation approaches currently used for cardiomyocyte differentiation from pluripotent stem cells.

\subsection{Embryoid Body Formation and Spontaneous Cardiomyo-} cyte Differentiation. The initial observation that hESCs could mature into spontaneously contracting cardiomyocyte-like cells was reported ten years ago when hESCs were cultured in suspension and formed three-dimensional aggregates called embryoid bodies $[6,59]$. Within the embryoid body, derivatives of the three germ layers (ectoderm, endoderm, and mesoderm) develop spontaneously. Within these mixed population of cells contracting areas with functional properties of cardiomyocytes can be detected. Cardiomyocytes are one of the first cell types induced from pluripotent stem cells in embryoid bodies, where cell to cell interactions stimulate the expression of markers for mesodermal and early cardiac cell lineages [60]. Typically, the embryoid bodies are plated on a matrix-coated tissue culture plate for further differentiation, and within a few days after plating, contracting outgrowths with cardiomyocyte characteristics can be observed [10]. As for human iPS cells, cardiomyocyte induction using embryoid body method was reported for the first time in 2009 [12]. The spontaneous differentiation of cardiomyocytes from pluripotent stem cells in embryoid 
bodies is considered to be rather inefficient usually under $10 \%$ and is highly cell line dependent [6].

Cardiomyocyte induction in the embryoid body-based differentiation system has also proven quite variable partly due to the heterogeneity among the aggregates that may, for example, differ in size and morphology. One strategy to address this issue was by adoption of the hanging drop method generally used with mESC [61]. However, this method has not been very successful with hESCs regardless of more consistency in the embryoid body formation. As an alternative, the forced-aggregation method was introduced, in which a defined number of dissociated hESCs were centrifuged into a round-bottomed ultra-low attachment 96well plate which allowed for better control of the embryoid body size [62]. Although this method was quite reproducible, as well as considered fairly practical and efficient, the forced-aggregation method was not originally developed for cardiomyocyte differentiation [62].

At that time when embryoid body cardiac differentiation method was introduced, limited information regarding the mechanisms underlying cardiogenesis in human pluripotent stem cells was available. Later, it has become evident that the differentiation process can be manipulated by the addition of growth factors, morphogenes, or by transgenic modifications to direct the pluripotent stem cells toward the cardiac cell fate. Spontaneous differentiation of hESCs, cultured as aggregates or embryoid bodies, has been shown to be enhanced by demethylating agent 5-aza-deoxycytidine [61]. By using the embryoid body cardiac differentiation method with 5-aza-deoxycutidine, between $8 \%$ and $70 \%$ of the embryoid bodies showed beating areas, and $2 \%$ to $70 \%$ of the beating areas consisted of cardiomyocytes [61]. Low oxygen tension has been shown to increase the number of cardiomyocytes from hESCs in bioreactors. Cardiac differentiation at $4 \%$ oxygen increases the total cell number by $30 \%-47 \%$ as well as some cardiac markers when compared with $20 \%$ oxygen [63]. Electrical stimulation with EB differentiation method has also been shown to enhance cardiac differentiation of hESCs through mechanisms associated with the intracellular generation of ROS [64]. Although many other approaches have been used to generate cardiomyocytes from pluripotent stem cells, the embryoid body formation in suspension cultures remains widely applied method to induce cardiomyocyte differentiation largely due to its simple and inexpensive nature.

3.2. Coculture of Pluripotent Stem Cells with Cardioinductive Cell Types. Another approach for cardiac differentiation was inspired by developmental studies indicating the critical role of anterior endoderm in the cardiac induction of adjacent mesodermal structures [65-67] and has been widely applied to induce cardiomyocyte differentiation in vitro. The method is based on coculture of pluripotent stem cells with a visceral endoderm-like cell line (END-2), derived from mouse P19 embryonal carcinoma (EC) cells, which results in the formation of beating clusters of cells that also display characteristics of cardiomyocytes $[9,68]$. The cardiac differentiation efficiency of the method can be enhanced in the absence of serum and with ascorbic acid. Ascorbic acid has been shown to upregulate late-stage markers of cardiogenesis [69]. Others as well as our group has found that this differentiation method works comparably well with iPS cell lines [70]. An END-2 conditioned media (END-2$\mathrm{CM}$ ) system has also been demonstrated to induce robust differentiation of cardiomyocytes in hESC-derived embryoid bodies [71-73]. Cardiomyocyte differentiation from pluripotent stem cells occurs within 12 days of co-culture with END-2 cells. Based on cardiomyocyte phenotype and electrophysiology, the majority of pluripotent stem cellderived cardiomyocytes resemble human fetal ventricular cardiomyocytes [9]. However, the cardiac differentiation efficiency from standard END-2 co-culture experiments is usually fairly low.

Based on the knowledge from developmental biology, the cardioinductive signals are thought to originate from direct cell to cell contact and/or secreted factors from the END-2 cells which stimulate the presence of embryonic endoderm [71]. Although the exact mechanism of END2 cardiac induction is still unclear, the transcriptome and secretome of END-2 cells have been described [74, 75]. Cardiac induction by END-2-CM can be at least partly mimicked by insulin depletion [72], inhibition of p38 MAPK [66], and addition of prostaglandin E [73]. END-2 cells have been shown to clear insulin from the medium and to secrete more $\mathrm{PGI}_{2}$ than any other type of mouse cells which lack the cardiac inductive effect $[72,73]$. Interestingly high concentrations of insulin appear to favor differentiation to neuroectoderm, and blocking p38 MAPK further enhances cardiac differentiation [71]. p38 MAPK signaling has been found to be highly active for the neuroectoderm formation and to be inhibitor of cardiomyogenesis, and thus blocking of this pathway may favor meso/endoderm differentiation [71]. These modifications to the END-2 co-culture protocol have been reported to result in preparations of $20 \%-25 \%$ cardiomyocytes. Identifying further cardiomyocyte inducing factors from the END-2 cells may provide opportunities to develop defined and more efficient process of differentiation for the induction of stem cells to cardiomyocytes and cardiac progenitors. Recently, a method for inducing maturation by replating the cardiomyocytes initially differentiated in coculture with END-2 cells on to fresh END-2 cells followed by a short three-dimensional culturing step was described [76]. The method enables cardiomyocyte maintenance for up to 1 year with increasing maturation in terms of their electrophysiological properties as well as increase in the number of pacemaker cells.

\subsection{Guided Cardiomyocyte Differentiation with Specific Fac-} tors. The signaling pathways regulating the cardiogenesis can be recapitulated in cell culture by the addition of specific growth factors such as FGFs, BMPs, and Wnts. Several studies have shown that combinations of BMP4, Wnt3a and Activin A induce gastrulation-like events and meso/endoderm development in pluripotent stem cells [77-79]. At least a part of the cardioinductive activity of anterior endoderm is mediated by growth factors belonging to the 
TGF $\beta$-superfamily $[80,81]$, and a guided cardiac differentiation involving two TGF $\beta$-family members, Activin A and BMP4, has been described [27]. In this approach, based on a high-density monolayer, pluripotent stem cells are cultured in a feeder cell-free system and cardiomyocyte differentiation is induced by a defined serum-free medium, supplemented sequentially with BMP4 and Activin A. The growth factors are then removed, and the cells are maintained in serumfree medium for an additional 2-3 weeks in the absence of exogenous growth factors. Spontaneously contracting areas are generally observed approximately 10 days after induction with Activin A, and enzymatically dissociated preparations at three weeks after induction typically consist of $>30 \%$ cardiomyocytes [27]. Both hESCs and iPS cells have been differentiated to cardiomyocytes by using this approach [17, 27].

Another protocol also involves TGF $\beta$-family molecules but also exploits the important roles of canonical Wnt signaling in cardiogenesis. Canonical Wnt signaling exerts stagedependent effects on cardiac differentiation: it is required for mesoderm induction but must be inhibited later for the induction of precardiac mesoderm $[55,56]$. Based on this information, a guided embryoid body differentiation protocol was developed involving induction of a primitive streak-like population in addition to formation of cardiac mesoderm with Activin A, BMP4, bFGF, and VEGF followed by cardiac specification with the Wnt inhibitor, Dkk-1 [57]. This protocol has been described to produce populations consisting of $\sim 40 \%-50 \%$ cardiomyocytes. The protocol was further enhanced by sorting the differentiating cultures for an early cardiovascular progenitor based on expression of the Flk-1 (also known as KDR). The early differentiating embryoid bodies include two $\mathrm{KDR}^{+}$populations: an early hemangioblast population (i.e., hematopoietic and endothelial progenitors) and another multipotent cardiovascular progenitor population that can be distinguished at 5-6 days after induction based on their differential expression of KDR and the stem cell marker c-kit [82]. In particular, if $\mathrm{KDR}^{\text {high }} / \mathrm{c}-\mathrm{kit}^{+}$cardiovascular progenitors are selected by fluorescence-activated cell sorting (FACS) at this timepoint and then replated in monolayer cultures, they subsequently differentiate into highly enriched preparation of cardiomyocytes, endothelial cells, and smooth muscle cells. Mesendoderm formation has also been induced by Wnt $3 \mathrm{~A}$, an activator of the canonical $\mathrm{Wnt} / \beta$ catenin signaling pathway in cardiac differentiation protocol [60]. In this protocol, hESCs were transiently treated with Wnt3A or BMP4, in the initial steps of embryoid body formation, and then subsequently decreased the amounts of serum and insulin in the culture medium [60].

Another recent report described the cardiac differentiation of pluripotent stem cells with BMP2, acting in a combinatorial manner with Wnt3, whose expression was triggered by the morphogen, to drive pluripotent stem cells toward an early mesodermal and cardiogenic fate in vitro. BMP2-induced Oct- $4^{+}$and SSEA- $1^{+}$cells give rise to endo/mesendodermal cells secreting cardiogenic factors, further directing the cell fate toward a cardiac phenotype when plated on MEFs releasing bFGF [5]. The addition of
PDGF or VEGF to BMP2-induced SSEA- $1^{+}$cells cultured on MEFs further directs the fate of the cells toward a smooth muscle and endothelial phenotype.

Chemical biology offers alternative means for discovering novel cellular signaling molecules mediating pluripotent stem cell cardiogenesis. As a consequence, high-throughput molecular screening technology has been exploited to search for compounds with the potential to induce cardiomyogenesis in vitro. To date, a few studies have published results from such screening approaches, describing the identification of novel small molecules that appear to stimulate the generation of cardiomyocytes from pluripotent stem cells, including cardiogenols, ascorbic acid, isoxazolylserines, sulfonyl hydrazones, and DMSO [69]. All of these molecules were identified based on their ability to upregulate late-stage markers of cardiogenesis. While some clearly have many effects on cells such as DMSO and ascorbic acid, others are probably more selective. Whether these factors have direct role in cardiogenesis or if they stimulate certain other cell populations which in turn activate cardiac development remains to be determined.

3.4. Cardiac Progenitor Cells. A growing evidence suggest that all three major cardiac cell lineages may arise from a common multipotent cardiovascular progenitor cell population originating in primitive streak and displaying specific expression of markers such as Flk-1, c-kit, and Isl-1 [5, 57, 82-84]. These cardiovascular progenitor cells have recently also been identified in early pluripotent stem cell derivatives $[5,57]$. Due to their proliferative capacity in culture, these cell populations would be ideal for upscaling in vitro. Furthermore, these early cardiac restricted precursor cells would allow for the establishment of progenitor cell based in vitro models for uncovering the early events of cardiogenesis. Strategies that might improve cardiomyocyte yields through stimulation of proliferation of committed progenitors might also be valuable. Information in regard to the signals that stimulate the replication of committed progenitors is still lacking; however, activation of canonical Wnt signaling has been demonstrated to expand the pool of $\mathrm{Nkx} 2.5^{+}$, and Isl1 $1^{+}$ early cardiac progenitors $[39,54,60,85]$, and the activation of the Notch pathway in immature cardiomyocytes has been shown to prolong their period of replicative competence [86, 87]. Other suggested mediators that might hold committed progenitors in a proliferative state are the GSK-3 inhibitor BIO [88], p38 MAPK inhibition [89], and the PI3K/Akt pathway [90].

\section{Enrichment Strategies of Stem Cell-Derived Cardiomyocytes}

Despite the tremendous progress in the development of current cardiac differentiation protocols, none of the currently available protocols results in homogenous populations of cardiomyocytes. One of the challenges over the last years has been to develop robust isolation techniques that allow scalable purification of cardiomyocytes and specific cardiac subtypes. The most straightforward approach is 
mechanical isolation based on manual dissection of the spontaneously contracting cardiac cells. The microdissected cells from even relatively low-purity cell population can include up to $70 \%$ cardiomyocytes $[6,9,24]$. Another fairly exploited approach presenting significant improvements to the enrichment process is Percoll density gradient centrifugation, which takes advantage of the unique buoyant properties of cardiomyocytes. Percoll centrifugation can result in a three- to sevenfold enrichment of cardiomyocytes and has been applied for enzymatically dispersed cells from embryoid bodies and for guided differentiation protocols [7, 22, 27, 77]. However, these enrichment protocols have disadvantages in regard to insufficient purity, fairly labor intensive procedure, and lack of scalability.

A recent study utilized an endogenously expressed surface marker, ALCAM, to isolate cardiomyocytes from a mixed population of differentiated cells [78]. This approach, however, has proven rather challenging for purifying cardiomyocytes from pluripotent stem cells due to the limitation of available cardiomyocyte-specific cell-surface markers. Another recent study demonstrated that a fluorescent dye labeling mitochondria could be used to selectively mark human pluripotent stem cell-derived cardiomyocytes and, subsequently, utilized in the enrichment of cardiomyocytes (>99\% purity) by fluorescence-activated cell sorting [91]. Other recent reports have demonstrated the guided differentiation and subsequent isolation of an early population of cardiovascular progenitors, expressing Oct4, SSEA-1, and Mesp1. The isolation of the progenitors was based on cell sorting using an anti-SSEA-1 antibody allowing separation of cells expressing mRNAs and proteins encoding mesodermal and cardiac markers $[5,92]$.

To date, the highest levels of cardiac purity have been obtained using genetic selection techniques. In this strategy, undifferentiated pluripotent stem cells are genetically modified to carry either a reporter gene, usually a green fluorescence protein (EGFP) or mammalian selection gene (e.g., antibiotic resistance) under the transcriptional control of a cardiac-specific promoter. The transgenic cells are then induced to differentiate and selected based on activation of the cardiac-specific promoter. While the major disadvantage of this approach is that it entails the usual risks of genetic modification (e.g., insertional oncogenesis), it is capable of a significant degree of cardiac enrichment [79, 93]. Genetic selection based on activation of either the human $\alpha$-MHC $[94,95]$ or MLC2v $[96,97]$ promoters has been shown to generate populations of $>90 \%$ human pluripotent stem cellderived cardiomyocytes. To sum up, most of the recently published cardiomyocyte enrichment studies demonstrate the advantages of using the transgenic strategy based on cardiac-specific drug resistance selection, either alone or in a combination with the reporter gene approach [73, 98, 99]. The influence of other cell types on cardiac differentiation is one aspect still to be further studied to determine at which state purification would be optimal [100]. While generally considered useful for in vitro applications, improvements and/or alternative strategies need to be developed to overcome the additional hurdles before introducing genetically modified cells into clinical cell therapy.

\section{Characteristics of Pluripotent Stem Cell-Derived Cardiomyocytes}

During recent years, a number of published studies have described the basic characteristics of pluripotent stem cell-derived cardiomyocytes. In these reports, cell analysis has been based on the expression of specific molecular markers for cardiomyocytes, structural architechture, and functionality. Although substantial heterogeneity has been reported, in general, $30 \%-60 \%$ of the cells in isolated beating areas display markers and other features of cardiomyocytes [6, 101-103]. Pluripotent stem cell-derived cardiomyocytes usually have less defined rod shape compared to their mature adult counterparts. In addition, pluripotent stem cell-derived cardiomyocytes display multinucleation at a very limited frequency $(<1 \%)$ [101] compared to adult human cardiomyocytes (20\%). At the ultrastructure level pluripotent stem cell-derived cardiomyocytes show clearly idenfiable sarcomeres with A, I, and Z bands and intercalated discs with gap juctions and desmosomes, and these cells share similarities with adult cardiomyocytes although the myofibrillar and sarcomeric organization indicate an immature phenotype in the stem cell-derived population $[6,61$, $101,102]$. In the vicinity of the sarcomeres, mitochonrdia are also present.

On a molecular level, several markers expressed by cardiomyocytes are also expressed by pluripotent stem cell-derived cardiomyocytes, including transcription factors, structural proteins, hormones, ion-channels, and tight junction proteins $[6-9,61,67,103]$. Expression of early cardiac-specific transcription factors involved in cardiogenesis such as GATA-4, Nkx2.5, Isl-1, Tbx-5, Tbx-20, and Mef2c is generally observed also in the pluripotent stem cell-derived cardiomyocytes $[6,7,61,67,103]$. In addition to structural proteins including sarcomeric proteins $\alpha$ actinin, cardiac troponins $\mathrm{T}$, and I, sarcomere myosin heavy chain (MHC), atrial- and ventricular myosin light chains (MLC-2A and MLC-2V), desmin, and tropomyosin, gap junction proteins are also expressed [7-9]. The presence of other cardiac and muscle-specific proteins including atrial natriuretic peptide (ANP), creatine kinase-MB, and myoglobin has also been described in several reports [7, 104]. Troponin complex is located on the thin filament of striated muscles and regulates muscle contraction in response to alterations in intracellular calcium ion concentrations.

More important, however, are the functional characteristics of the cells, and different pharmacological and electrophysiological approaches have been used to examine these properties. As in mature cardiomyocytes, the trigger for contraction in pluripotent stem cell-derived cardiomyocytes is a rise in intracellular calcium $[9,105]$. However, the regulation of intracellular calcium handling has been shown to differ between pluripotent stem cellderived cardiomyocytes and mature adult cardiomyocytes, most likely due to the apparently immature sarcoplasmic reticulum which has been suggested to be caused by lack of expression of phospholamban and calsequestrin, which are two of the main intracellular calcium handling 
proteins [105-107]. One major advantage of cardiomyocytes derived from pluripotent stem cells is that they can be maintained in culture for extended time periods even months without losing their spontaneous contractile capacity. Although pluripotent stem cell-derived cardiomyocytes show unambiguous cardiac-type action potentials (AP), these cells exhibit comparatively immature AP parameters such as automaticity, a slower AP upstroke, and a relatively depolarized maximum diastolic potential $[8,108]$. Several studies have demonstrated that pluripotent stem cell-derived cardiomyocytes exhibit spontaneous contractile activity that could be modulated by drugs such as isoproterenol and carbachol, and thus these cells respond to alpha/beta-adrenergic- and muscarinic stimuli further indicating that the cells express specific surface membrane receptors coupled to a signaling pathway that activate ion channels, membrane transporters, and myofilament proteins $[6,7,103]$. In contrast to a typical mature cardiomyocyte characteristic increase in contraction amplitude in response to increased stimulation in the (i.e., the force-frequency relation) in the adult myocardium, pluripotent stem cellderived cardiomyocytes have been reported to respond in the opposite manner and display negative force-frequency relations [104].

In general, cardiomyocyte induction from pluripotent stem cells results in mixtures of ventricular-like, atrial-like, and pacemaker-like cells defined by intracellular electrophysiological measurements of action potentials (APs). As shown in voltage-clamp studies, pluripotent stem cell-derived cardiomyocytes exhibit expected ionic currents, such as fast sodium current, L-type calcium current, pacemaker currents, as well as transient outward and inward rectifier potassium currents [9, 108] Interestingly, different differentiation protocols seem to affect the ratios of these cardiac cell types. While most differentiation protocols based on embryoid bodies/cell aggregates result in more or less equal numbers of ventricular- and atrial-like cells, cardiac induction by END-2 co-culture generally results in cell population where the majority of the cardiomyocytes display ventricular-like phenotype based on morphological and electrophysiological parameters [9].

In summary, based on the gene expression profile and the structural-, electrophysiological-, and pharmacological properties of the pluripotent stem cell-derived cardiomyocytes they possess immature phenotype and appear to have an immature sarcoplasmic reticulum function. The cardiac phenotype of iPS cell-derived cardiomyocytes seems to be comparable to that of hESC-derived cardiomyocytes [17]. Pluripotent stem cell-derived cardiomyocytes have been shown to mature over time in culture but without carrying through to full maturity. Thus, additional research is needed to find novel strategies to mature pluripotent stem cellderived cardiomyocytes in vitro. Nevertheless, even if some functional properties of pluripotent stem cell-derived cardiomyocytes apparently differ from the mature cells present in adult myocardium the in vitro generated cardiomyocytes have a basal functionality and can still provide a useful model for molecular cardiology.

\section{Conclusion and Future Perspectives}

Cardiac differentiation is a dynamic process consisting of complex signaling network, and although various signaling pathways and growth factors have been implicated in the development of specialized cardiac subtypes, only limited information about the mechanisms underlaying cardiogenesis in human pluripotent stem cells is currently available. Thus, the differentiation of pluripotent stem cells toward cardiomyocytes is still poorly defined compared with the other cell fates. A number of differentiation protocols have been described to generate cardiomyocytes from pluripotent stem cells. Collectively, various cardiac differentiation studies demonstrate how the exposure of various growth factors to pluripotent stem cells, at an accurate timing and dose, is essential for directing the differentiation process from early mesendoderm via mesoderm towards a more specific cardiac fate. Despite the recent advances in the cardiac differentiation protocols, in most settings the cardiomyocyte differentiation is uncontrolled and inefficient remaining less than $10 \%$ [69]. Most of the iPS cell lines generated to date are subject to viral integration that may have an impact on the cardiogenesis of these cells. However, human iPS cells appear to have a cardiac potential highly comparable to hESCs, and iPS cells can be differentiated into cardiomyocytes using similar differentiation protocols [17]. Based on the variations of the protocols used and the efficiency at which pluripotent stem cells differentiate to cardiomyocytes, it appears that pluripotent stem cell lines including both hESC and iPS cell lines behave quite differently, implicating that the specific pluripotent stem cell line utilized might affect the final result. Thus, each pluripotent cell line may require a specific differentiation protocol for efficient induction of cardiogenesis further complicating the overall assignment. Evidently, a more indepth understanding of these mechanisms will improve the yields of pluripotent stem cell-derived cardiomyocytes for large-scale and clinical application.

The stem cell-derived cardiomyocytes described to date, generally resemble fetal cardiomyocytes exhibiting immature functional and structural characteristics compared to adult cardiomyocytes and mature only slowly in cell culture. Furthermore, the differentiated cells are mixed populations of noncardiac cells and cardiomyocytes with several subtypes (e.g., ventricular-, atrial-, and nodal type) and maturation stages. Currently, we are also lacking efficient ways to guide the cardiac subtype differentiation as well as to isolate cardiomyocytes and subtypes of cardiomyocytes from the heterogeneous pool of differentiating cells. Thus, efficient enrichment strategies for cardiomyocytes as well as different cardiac sub-types are urgently needed. A recent study provided a strategy for the enrichment of cardiomyocytes and in particular, the generation of a specific subtype of cardiomyocytes, nodal-like cells, without genetic modification. They utilized the activator of $\mathrm{Ca}^{2+}$-activated potassium channels of small and intermediate conductance (SKCas) on embryonic stem cells leading to induction of cardiac mesoderm and cardiomyocyte specification resulting in a strong enrichment of pacemaker-like cells [109]. 
Most of the current cardiac differentiation methods produce beating aggregates, but for many purposes, monolayer cardiac differentiation would be optimal. However, it has been shown that cell-to-cell interactions in the embryoid body and aggregate structures stimulate the expression of markers for mesendoderm and early cardiac cell lineages, which argues in favor of the three-dimensional cell aggregates for optimal pluripotent stem cell differentiation to cardiac myocytes [60]. Nevertheless, the current differentiation protocols produce cardiomyocytes that possess many promising capabilities and have wide-spread utility for basic research as well as pharmaceutical industry. In future, stem cell-derived cardiomyocytes are anticipated to have an enormous impact on the treatment of heart disease. The ability to induce iPS cells has raised the possibility to reprogram somatic cells to an alternative differentiated fate without first becoming a stem cell. Recently, it was shown that a combination of three transcription factors (Gata4, Mef2c, and Tbx5) reprogrammed cardiac or dermal fibroblasts directly into spontaneously contracting cardiomyocytes, expressing cardiac-specific markers [110]. These induced cardiomyocytes offer another important option to research, drug discovery and cell therapy towards cardiovascular regeneration.

\section{References}

[1] T. Meyer, P. Sartipy, F. Blind, C. Leisgen, and E. Guenther, "New cell models and assays in cardiac safety profiling," Expert Opinion on Drug Metabolism and Toxicology, vol. 3, no. 4, pp. 507-517, 2007.

[2] S. Dimmeler, J. Burchfield, and A. M. Zeiher, "Cell-based therapy of myocardial infarction," Arteriosclerosis, Thrombosis, and Vascular Biology, vol. 28, no. 2, pp. 208-216, 2008.

[3] C. E. Murry, L. J. Field, and P. Menasché, "Cell-based cardiac repair reflections at the 10-year point," Circulation, vol. 112, no. 20, pp. 3174-3183, 2005.

[4] P. Anversa, A. Leri, M. Rota et al., "Concise review: stem cells, myocardial regeneration, and methodological artifacts," Stem Cells, vol. 25, no. 3, pp. 589-601, 2007.

[5] G. Blin, D. Nury, S. Stefanovic et al., "A purified population of multipotent cardiovascular progenitors derived from primate pluripotent stem cells engrafts in postmyocardial infarcted nonhuman primates," Journal of Clinical Investigation, vol. 120, no. 4, pp. 1125-1139, 2010.

[6] I. Kehat, D. Kenyagin-Karsenti, M. Snir et al., "Human embryonic stem cells can differentiate into myocytes with structural and functional properties of cardiomyocytes," Journal of Clinical Investigation, vol. 108, no. 3, pp. 407-414, 2001.

[7] C. Xu, S. Police, N. Rao, and M. K. Carpenter, "Characterization and enrichment of cardiomyocytes derived from human embryonic stem cells," Circulation Research, vol. 91, no. 6, pp. 501-508, 2002.

[8] J. Q. He, Y. Ma, Y. Lee, J. A. Thomson, and T. J. Kamp, "Human embryonic stem cells develop into multiple types of cardiac myocytes: action potential characterization," Circulation Research, vol. 93, no. 1, pp. 32-39, 2003.

[9] C. Mummery, D. Ward-van Oostwaard, P. Doevendans et al., "Differentiation of human embryonic stem cells to cardiomyocytes: role of coculture with visceral endodermlike cells," Circulation, vol. 107, no. 21, pp. 2733-2740, 2003.
[10] C. Améen, R. Strehl, P. Björquist, A. Lindahl, J. Hyllner, and P. Sartipy, "Human embryonic stem cells: current technologies and emerging industrial applications," Critical Reviews in Oncology/Hematology, vol. 65, no. 1, pp. 54-80, 2008.

[11] J. A. Thomson, "Embryonic stem cell lines derived from human blastocysts," Science, vol. 282, no. 5391, pp. 11451147, 1998.

[12] J. Zhang, G. F. Wilson, A. G. Soerens et al., "Functional cardiomyocytes derived from human induced pluripotent stem cells," Circulation Research, vol. 104, no. 4, pp. e30-e41, 2009.

[13] L. Zwi, O. Caspi, G. Arbel et al., "Cardiomyocyte differentiation of human induced pluripotent stem cells," Circulation, vol. 120, no. 15, pp. 1513-1523, 2009.

[14] A. Haase, R. Olmer, K. Schwanke et al., "Generation of induced pluripotent stem cells from human cord blood," Cell Stem Cell, vol. 5, no. 4, pp. 434-441, 2009.

[15] H. Vidarsson, J. Hyllner, and P. Sartipy, "Differentiation of human embryonic stem cells to cardiomyocytes for in vitro and in vivo applications," Stem Cell Reviews and Reports, vol. 6, no. 1, pp. 108-120, 2010.

[16] S. R. Braam, R. Passier, and C. L. Mummery, "Cardiomyocytes from human pluripotent stem cells in regenerative medicine and drug discovery," Trends in Pharmacological Sciences, vol. 30, no. 10, pp. 536-545, 2009.

[17] K. Takahashi, K. Tanabe, M. Ohnuki et al., "Induction of pluripotent stem cells from adult human fibroblasts by defined factors," Cell, vol. 131, no. 5, pp. 861-872, 2007.

[18] J. Yu, M. A. Vodyanik, K. Smuga-Otto et al., "Induced pluripotent stem cell lines derived from human somatic cells," Science, vol. 318, no. 5858, pp. 1917-1920, 2007.

[19] I. Itzhaki, L. Maizels, I. Huber et al., "Modelling the long QT syndrome with induced pluripotent stem cells," Nature, vol. 471, no. 7337, pp. 225-229, 2011.

[20] A. Moretti, M. Bellin, A. Welling et al., "Patient-specific induced pluripotent stem-cell models for long-QT syndrome," New England Journal of Medicine, vol. 363, no. 15, pp. 1397-1409, 2010.

[21] I. Kehat, L. Khimovich, O. Caspi et al., "Electromechanical integration of cardiomyocytes derived from human embryonic stem cells," Nature Biotechnology, vol. 22, no. 10, pp. 1282-1289, 2004.

[22] M. A. Laflamme, J. Gold, C. Xu et al., "Formation of human myocardium in the rat heart from human embryonic stem cells," American Journal of Pathology, vol. 167, no. 3, pp. 663671, 2005.

[23] J. Leor, S. Gerecht, S. Cohen et al., "Human embryonic stem cell transplantation to repair the infarcted myocardium," Heart, vol. 93, no. 10, pp. 1278-1284, 2007.

[24] O. Caspi, I. Huber, I. Kehat et al., "Transplantation of human embryonic stem cell-derived cardiomyocytes improves myocardial performance in infarcted rat hearts," Journal of the American College of Cardiology, vol. 50, no. 19, pp. 1884-1893, 2007.

[25] L. W. van Laake, R. Passier, J. Monshouwer-Kloots et al., "Human embryonic stem cell-derived cardiomyocytes survive and mature in the mouse heart and transiently improve function after myocardial infarction," Stem Cell Research, vol. 1, no. 1, pp. 9-24, 2007.

[26] W. Dai, L. J. Field, M. Rubart et al., "Survival and maturation of human embryonic stem cell-derived cardiomyocytes in rat hearts," Journal of Molecular and Cellular Cardiology, vol. 43, no. 4, pp. 504-516, 2007. 
[27] M. A. Laflamme, K. Y. Chen, A. V. Naumova et al., "Cardiomyocytes derived from human embryonic stem cells in pro-survival factors enhance function of infarcted rat hearts," Nature Biotechnology, vol. 25, no. 9, pp. 1015-1024, 2007.

[28] T. J. Nelson, A. Martinez-Fernandez, S. Yamada, C. PerezTerzic, Y. Ikeda, and A. Terzic, "Repair of acute myocardial infarction with induced pluripotent stem cells induced by human stemness factors," Circulation, vol. 120, no. 5, pp. 408-416, 2009.

[29] F. F. Yi, L. Yang, Y. H. Li, PI. X. Su, J. Cai, and X. C. Yang, "Electrophysiological development of transplanted embryonic stem cell-derived cardiomyocytes in the hearts of syngeneic mice," Archives of Medical Research, vol. 40, no. 5, pp. 339-344, 2009.

[30] Y. M. Zhang, C. Hartzell, M. Narlow, and S. C. Dudley Jr., "Stem cell-derived cardiomyocytes demonstrate arrhythmic potential," Circulation, vol. 106, no. 10, pp. 1294-1299, 2002.

[31] D. Srivastava and K. N. Ivey, "Potential of stem-cell-based therapies for heart disease," Nature, vol. 441, no. 7097, pp. 1097-1099, 2006.

[32] Y. Hiroi, S. Kudoh, K. Monzen et al., “Tbx5 associates with Nkx2-5 and synergistically promotes cardiomyocyte differentiation," Nature Genetics, vol. 28, no. 3, pp. 276-280, 2001.

[33] T. Peterkin, A. Gibson, and R. Patient, "GATA-6 maintains BMP-4 and Nkx2 expression during cardiomyocyte precursor maturation," EMBO Journal, vol. 22, no. 16, pp. 4260 4273, 2003.

[34] T. F. Plageman Jr. and K. E. Yutzey, "Differential expression and function of Tbx5 and Tbx20 in cardiac development," Journal of Biological Chemistry, vol. 279, no. 18, pp. $19026-$ 19034, 2004.

[35] P. Riley, L. Anson-Cartwright, and J. C. Cross, "The Hand1 bHLH transcription factor is essential for placentation and cardiac morphogenesis," Nature Genetics, vol. 18, no. 3, pp. 271-275, 1998.

[36] A. J. Watt, M. A. Battle, J. Li, and S. A. Duncan, "GATA4 is essential for formation of the proepicardium and regulates cardiogenesis," Proceedings of the National Academy of Sciences of the United States of America, vol. 101, no. 34, pp. 12573-12578, 2004.

[37] A. Bondue, G. Lapouge, C. Paulissen et al., "Mesp1 acts as a master regulator of multipotent cardiovascular progenitor specification," Cell stem cell, vol. 3, no. 1, pp. 69-84, 2008.

[38] R. C. Lindsley, J. G. Gill, T. L. Murphy et al., "Mesp1 coordinately regulates cardiovascular fate restriction and epithelial-mesenchymal transition in differentiating ESCs," Cell stem cell, vol. 3, no. 1, pp. 55-68, 2008.

[39] M. J. Marvin, G. Di Rocco, A. Gardiner, S. M. Bush, and A. B. Lassar, "Inhibition of Wnt activity induces heart formation from posterior mesoderm," Genes and Development, vol. 15, no. 3, pp. 316-327, 2001.

[40] T. Mima, H. Ueno, D. A. Fischman, L. T. Williams, and T. Mikawa, "Fibroblast growth factor receptor is required for in vivo cardiac myocyte proliferation at early embryonic stages of heart development," Proceedings of the National Academy of Sciences of the United States of America, vol. 92, no. 2, pp. 467-471, 1995.

[41] G. Winnier, M. Blessing, P. A. Labosky, and B. L. M. Hogan, "Bone morphogenetic protein-4 is required for mesoderm formation and patterning in the mouse," Genes and Development, vol. 9, no. 17, pp. 2105-2116, 1995.
[42] H. Zhang and A. Bradley, "Mice deficient for BMP2 are nonviable and have defects in amnion/chorion and cardiac development," Development, vol. 122, no. 10, pp. 2977-2986, 1996.

[43] A. E. Pasquinelli, S. Hunter, and J. Bracht, "MicroRNAs: a developing story," Current Opinion in Genetics and Development, vol. 15, no. 2, pp. 200-205, 2005.

[44] Y. Zhao and D. Srivastava, "A developmental view of microRNA function," Trends in Biochemical Sciences, vol. 32, no. 4, pp. 189-197, 2007.

[45] T. E. Callis, Z. Deng, J. F. Chen, and DA. Z. Wang, "Muscling through the microRNA world," Experimental Biology and Medicine, vol. 233, no. 2, pp. 131-138, 2008.

[46] E. van Rooij, N. Liu, and E. N. Olson, "MicroRNAs flex their muscles," Trends in Genetics, vol. 24, no. 4, pp. 159-166, 2008.

[47] Z. Wang, X. Luo, Y. Lu, and B. Yang, "miRNAs at the heart of the matter," Journal of Molecular Medicine, vol. 86, no. 7, pp. 771-783, 2008.

[48] K. N. Ivey, A. Muth, J. Arnold et al., "MicroRNA regulation of cell lineages in mouse and human embryonic stem cells," Cell Stem Cell, vol. 2, no. 3, pp. 219-229, 2008.

[49] D. Nury, T. Neri, and M. Pucéat, "Human embryonic stem cells and cardiac cell fate," Journal of Cellular Physiology, vol. 218, no. 3, pp. 455-459, 2009.

[50] P. Gadue, T. L. Huber, P. J. Paddison, and G. M. Keller, "Wnt and TGF- $\beta$ signaling are required for the induction of an in vitro model of primitive streak formation using embryonic stem cells," Proceedings of the National Academy of Sciences of the United States of America, vol. 103, no. 45, pp. 1680616811, 2006.

[51] R. C. Lindsley, J. G. Gill, M. Kyba, T. L. Murphy, and K. M. Murphy, "Canonical Wnt signaling is required for development of embryonic stem cell-derived mesoderm," Development, vol. 133, no. 19, pp. 3787-3796, 2006.

[52] A. C. Foley, O. Korol, A. M. Timmer, and M. Mercola, "Multiple functions of Cerberus cooperate to induce heart downstream of Nodal," Developmental Biology, vol. 303, no. 1, pp. 57-65, 2007.

[53] A. C. Foley and M. Mercola, "Heart induction by Wnt antagonists depends on the homeodomain transcription factor Hex," Genes and Development, vol. 19, no. 3, pp. 387396, 2005.

[54] V. A. Schneider and M. Mercola, "Wnt antagonism initiates cardiogenesis in Xenopus laevis," Genes and Development, vol. 15, no. 3, pp. 304-315, 2001.

[55] A. T. Naito, I. Shiojima, H. Akazawa et al., "Developmental stage-specific biphasic roles of $\mathrm{Wnt} / \beta$-catenin signaling in cardiomyogenesis and hematopoiesis," Proceedings of the National Academy of Sciences of the United States of America, vol. 103, no. 52, pp. 19812-19817, 2006.

[56] S. Ueno, G. Weidinger, T. Osugi et al., "Biphasic role for $\mathrm{Wnt} / \beta$-catenin signaling in cardiac specification in zebrafish and embryonic stem cells," Proceedings of the National Academy of Sciences of the United States of America, vol. 104, no. 23, pp. 9685-9690, 2007.

[57] L. Yang, M. H. Soonpaa, E. D. Adler et al., "Human cardiovascular progenitor cells develop from a $\mathrm{KDR}^{+}$embryonicstem-cell-derived population," Nature, vol. 453, no. 7194, pp. 524-528, 2008.

[58] V. C. Chen, R. Stull, D. Joo, X. Cheng, and G. Keller, "Notch signaling respecifies the hemangioblast to a cardiac fate," Nature Biotechnology, vol. 26, no. 10, pp. 1169-1178, 2008. 
[59] J. Itskovitz-Eldor, M. Schuldiner, D. Karsenti et al., "Differentiation of human embryonic stem cells into embryoid bodies compromising the three embryonic germ layers," Molecular Medicine, vol. 6, no. 2, pp. 88-95, 2000.

[60] T. H. Tran, X. Wang, C. Browne et al., "Wnt3a-induced mesoderm formation and cardiomyogenesis in human embryonic stem cells," Stem Cells, vol. 27, no. 8, pp. 1869-1878, 2009.

[61] B. S. Yoon, S. J. Yoo, J. E. Lee, S. You, H. T. Lee, and H. S. Yoon, "Enhanced differentiation of human embryonic stem cells into cardiomyocytes by combining hanging drop culture and 5-azacytidine treatment," Differentiation, vol. 74, no. 4, pp. 149-159, 2006.

[62] E. S. Ng, R. P. Davis, L. Azzola, E. G. Stanley, and A. G. Elefanty, "Forced aggregation of defined numbers of human embryonic stem cells into embryoid bodies fosters robust, reproducible hematopoietic differentiation," Blood, vol. 106, no. 5, pp. 1601-1603, 2005.

[63] S. Niebruegge, C. L. Bauwens, R. Peerani et al., "Generation of human embryonic stem cell-derived mesoderm and cardiac cells using size-specified aggregates in an oxygencontrolled bioreactor," Biotechnology and Bioengineering, vol. 102, no. 2, pp. 493-507, 2009.

[64] E. Serena, E. Figallo, N. Tandon et al., "Electrical stimulation of human embryonic stem cells: cardiac differentiation and the generation of reactive oxygen species," Experimental Cell Research, vol. 315, no. 20, pp. 3611-3619, 2009.

[65] J. Synnergren, K. Åkesson, K. Dahlenborg et al., "Molecular signature of cardiomyocyte clusters derived from human embryonic stem cells," Stem Cells, vol. 26, no. 7, pp. 18311840, 2008.

[66] F. Cao, R. A. Wagner, K. D. Wilson et al., "Transcriptional and functional profilling of human embryonic stem cell-derived cardiomyocytes," PLoS One, vol. 3, no. 10, Article ID e3474, 2008.

[67] X. Q. Xu, S. Y. Soo, W. Sun, and R. Zweigerdt, "Global expression profile of highly enriched cardiomyocytes derived from human embryonic stem cells," Stem Cells, vol. 27, no. 9, pp. 2163-2174, 2009.

[68] R. Passier, D. Ward-Van Oostwaard, J. Snapper et al., "Increased cardiomyocyte differentiation from human embryonic stem cells in serum-free cultures," Stem Cells, vol. 23, no. 6, pp. 772-780, 2005.

[69] E. Willems, P. J. Bushway, and M. Mercola, "Natural and synthetic regulators of embryonic stem cell cardiogenesis," Pediatric Cardiology, vol. 30, no. 5, pp. 635-642, 2009.

[70] C. Freund, R. P. Davis, K. Gkatzis, D. Ward-van Oostwaard, and C. L. Mummery, "The first reported generation of human induced pluripotent stem cells (iPS cells) and iPS cell-derived cardiomyocytes in the Netherlands," Netherlands Heart Journal, vol. 18, no. 1, pp. 51-54, 2010.

[71] R. Graichen, X. Xu, S. R. Braam et al., "Enhanced cardiomyogenesis of human embryonic stem cells by a small molecular inhibitor of p38 MAPK," Differentiation, vol. 76, no. 4, pp. 357-370, 2008.

[72] C. Freund, D. W. V. Oostwaard, J. Monshouwer-Kloots et al., "Insulin redirects differentiation from cardiogenic mesoderm and endoderm to neuroectoderm in differentiating human embryonic stem cells," Stem Cells, vol. 26, no. 3, pp. 724-733, 2008.

[73] X. Q. Xu, R. Graichen, S. Y. Soo et al., "Chemically defined medium supporting cardiomyocyte differentiation of human embryonic stem cells," Differentiation, vol. 76, no. 9, pp. 958970, 2008.
[74] Y. Kang, J. M. Nagy, J. M. Polak, and A. Mantalaris, "Proteomic characterization of the conditioned media produced by the visceral endoderm-like cell lines HepG2 and END2: toward a defined medium for the osteogenic/chondrogenic differentiation of embryonic stem cells," Stem Cells and Development, vol. 18, no. 1, pp. 77-92, 2009.

[75] D. K. Arrell, N. J. Niederländer, R. S. Faustino, A. Behfar, and A. Terzic, "Cardioinductive network guiding stem cell differentiation revealed by proteomic cartography of tumor necrosis factor $\alpha$-primed endodermal secretome," Stem Cells, vol. 26, no. 2, pp. 387-400, 2008.

[76] T. G. Otsuji, I. Minami, Y. Kurose, K. Yamauchi, M. Tada, and N. Nakatsuji, "Progressive maturation in contracting cardiomyocytes derived from human embryonic stem cells: qualitative effects on electrophysiological responses to drugs," Stem Cell Research, vol. 4, no. 3, pp. 201-213, 2010.

[77] C. Xu, S. Police, M. Hassanipour, and J. D. Gold, "Cardiac bodies: a novel culture method for enrichment of cardiomyocytes derived from human embryonic stem cells," Stem Cells and Development, vol. 15, no. 5, pp. 631-639, 2006.

[78] W. Rust, T. Balakrishnan, and R. Zweigerdt, "Cardiomyocyte enrichment from human embryonic stem cell cultures by selection of ALCAM surface expression," Regenerative Medicine, vol. 4, no. 2, pp. 225-237, 2009.

[79] E. Kolossov, Z. Lu, I. Drobinskaya et al., "Identification and characterization of embryonic stem cell-derived pacemaker and atrial cardiomyocytes," FASEB Journal, vol. 19, no. 6, pp. 577-579, 2005.

[80] W. C. Claycomb, N. A. Lanson Jr., B. S. Stallworth et al., "HL1 cells: a cardiac muscle cell line that contracts and retains phenotypic characteristics of the adult cardiomyocyte," Proceedings of the National Academy of Sciences of the United States of America, vol. 95, no. 6, pp. 2979-2984, 1998.

[81] M. Reppel, F. Pillekamp, K. Brockmeier et al., "The electrocardiogram of human embryonic stem cell-derived cardiomyocytes," Journal of Electrocardiology, vol. 38, no. 4, pp. 166-170, 2005.

[82] S. J. Kattman, T. L. Huber, and G. Keller, "Multipotent Flk-1 ${ }^{+}$ cardiovascular progenitor cells give rise to the cardiomyocyte, endothelial, and vascular smooth muscle lineages," Developmental Cell, vol. 11, no. 5, pp. 723-732, 2006.

[83] A. Moretti, L. Caron, A. Nakano et al., "Multipotent embryonic is $11^{+}$progenitor cells lead to cardiac, smooth muscle, and endothelial cell diversification," Cell, vol. 127, no. 6, pp. 1151-1165, 2006.

[84] L. Bu, X. Jiang, S. Martin-Puig et al., "Human ISL1 heart progenitors generate diverse multipotent cardiovascular cell lineages," Nature, vol. 460, no. 7251, pp. 113-117, 2009.

[85] A. Klaus and W. Birchmeier, "Developmental signaling in myocardial progenitor cells: a comprehensive view of bmpand wnt/ $\beta$-catenin signaling," Pediatric Cardiology, vol. 30, no. 5, pp. 609-616, 2009.

[86] A. Raya, C. M. Koth, D. Büscher et al., "Activation of Notch signaling pathway precedes heart regeneration in zebrafish," Proceedings of the National Academy of Sciences of the United States of America, vol. 100, no. 1, pp. 11889-11895, 2003.

[87] M. S. Rones, K. A. McLaughlin, M. Raffin, and M. Mercola, "Serrate and Notch specify cell fates in the heart field by suppressing cardiomyogenesis," Development, vol. 127, no. 17, pp. 3865-3876, 2000.

[88] AI. S. Tseng, F. B. Engel, and M. Keating, "The GSK-3 inhibitor BIO promotes proliferation in mammalian cardiomyocytes," Chemistry and Biology, vol. 13, no. 9, pp. 957963, 2006. 
[89] F. B. Engel, M. Schebesta, M. T. Duong et al., "p38 MAP kinase inhibition enables proliferation of adult mammalian cardiomyocytes," Genes and Development, vol. 19, no. 10, pp. 1175-1187, 2005.

[90] T. C. McDevitt, M. A. Laflamme, and C. E. Murry, "Proliferation of cardiomyocytes derived from human embryonic stem cells is mediated via the IGF/PI 3-kinase/Akt signaling pathway," Journal of Molecular and Cellular Cardiology, vol. 39, no. 6, pp. 865-873, 2005.

[91] F. Hattori, H. Chen, H. Yamashita et al., "Nongenetic method for purifying stem cell-derived cardiomyocytes," Nature Methods, vol. 7, no. 1, pp. 61-66, 2010.

[92] J. Leschik, S. Stefanovic, B. Brinon, and M. Pucéat, "Cardiac commitment of primate embryonic stem cells," Nature Protocols, vol. 3, no. 9, pp. 1381-1387, 2008.

[93] Y. Shiba, K. D. Hauch, and M. A. Laflamme, "Cardiac applications for human pluripotent stem cells," Current Pharmaceutical Design, vol. 15, no. 24, pp. 2791-2806, 2009.

[94] D. Anderson, T. Self, I. R. Mellor, G. Goh, S. J. Hill, and C. Denning, "Transgenic enrichment of cardiomyocytes from human embryonic stem cells," Molecular Therapy, vol. 15, no. 11, pp. 2027-2036, 2007.

[95] Q. X. Xu, R. Zweigerdt, S. Y. Soo et al., "Highly enriched cardiomyocytes from human embryonic stem cells," Cytotherapy, vol. 10, no. 4, pp. 376-389, 2008.

[96] I. Huber, I. Itzhaki, O. Caspi et al., "Identification and selection of cardiomyocytes during human embryonic stem cell differentiation," FASEB Journal, vol. 21, no. 10, pp. 25512563, 2007.

[97] J. D. Fu, P. Jiang, S. Rushing, J. Liu, N. Chiamvimonvat, and R. A. $\mathrm{Li}$, " $\mathrm{Na}^{+} / \mathrm{Ca}^{2+}$ exchanger is a determinant of excitationcontraction coupling in human embryonic stem cell-derived ventricular cardiomyocytes," Stem Cells and Development, vol. 19, no. 6, pp. 773-782, 2010.

[98] H. Kita-Matsuo, M. Barcova, N. Prigozhina et al., "Lentiviral vectors and protocols for creation of stable hESC lines for fluorescent tracking and drug resistance selection of cardiomyocytes," PLoS One, vol. 4, no. 4, Article ID e5046, 2009.

[99] W.-Z. Zhu, Y. Xie, K. W. Moyes, J. D. Gold, B. Askari, and M. A. Laflamme, "Neuregulin/ErbB signaling regulates cardiac subtype specification in differentiating human embryonic stem cells," Circulation Research, vol. 107, no. 6, pp. 776-786, 2010.

[100] C. Kim, M. Majdi, P. Xia et al., "Non-cardiomyocytes influence the electrophysiological maturation of human embryonic stem cell-derived cardiomyocytes during differentiation," Stem Cells and Development, vol. 19, no. 6, pp. 783-795, 2010.

[101] M. Snir, I. Kehat, A. Gepstein et al., "Assessment of the ultrastructural and proliferative properties of human embryonic stem cell-derived cardiomyocytes," American Journal of Physiology, vol. 285, no. 6, pp. H2355-H2363, 2003.

[102] J. Liu, D. F. Ji, W. S. Chung, and R. A. Li, "Functional sarcoplasmic reticulum for calcium handling of human embryonic stem cell-derived cardiomyocytes: insights for driven maturation," Stem Cells, vol. 25, no. 12, pp. 30383044, 2007.

[103] A. Norström, K. Åkesson, T. Hardarson, L. Hamberger, P. Björquist, and P. Sartipy, "Molecular and pharmacological properties of human embryonic stem cell-derived cardiomyocytes," Experimental Biology and Medicine, vol. 231, no. 11, pp. 1753-1762, 2006.
[104] I. Kehat, A. Gepstein, A. Spira, J. Itskovitz-Eldor, and L. Gepstein, "High-resolution electrophysiological assessment of human embryonic stem cell-derived cardiomyocytes: a novel in vitro model for the study of conduction," Circulation Research, vol. 91, no. 8, pp. 659-661, 2002.

[105] L. Sartiani, E. Bettiol, F. Stillitano, A. Mugelli, E. Cerbai, and M. E. Jaconi, "Developmental changes in cardiomyocytes differentiated from human embryonic stem cells: a molecular and electrophysiological approach," Stem Cells, vol. 25, no. 5, pp. 1136-1144, 2007.

[106] K. Dolnikov, M. Shilkrut, N. Zeevi-Levin et al., "Functional properties of human embryonic stem cell-derived cardiomyocytes," Annals of the New York Academy of Sciences, vol. 1047, pp. 66-75, 2005.

[107] O. Binah, K. Dolnikov, O. Sadan et al., "Functional and developmental properties of human embryonic stem cellsderived cardiomyocytes," Journal of Electrocardiology, vol. 40, no. 6, pp. S192-S196, 2007.

[108] M. Brito-Martins, S. E. Harding, and N. N. Ali, " $\beta_{1}$ - and $\beta_{2}$-adrenoceptor responses in cardiomyocytes derived from human embryonic stem cells: comparison with failing and non-failing adult human heart," British Journal of Pharmacology, vol. 153, no. 4, pp. 751-759, 2008.

[109] A. Kleger, T. Seufferlein, D. Malan et al., "Modulation of calcium-activated potassium channels induces cardiogenesis of pluripotent stem cells and enrichment of pacemaker-like cells," Circulation, vol. 122, no. 18, pp. 1823-1836, 2010.

[110] M. Ieda, J.-D. Fu, P. Delgado-Olguin et al., "Direct reprogramming of fibroblasts into functional cardiomyocytes by defined factors," Cell, vol. 142, no. 3, pp. 375-386, 2010. 

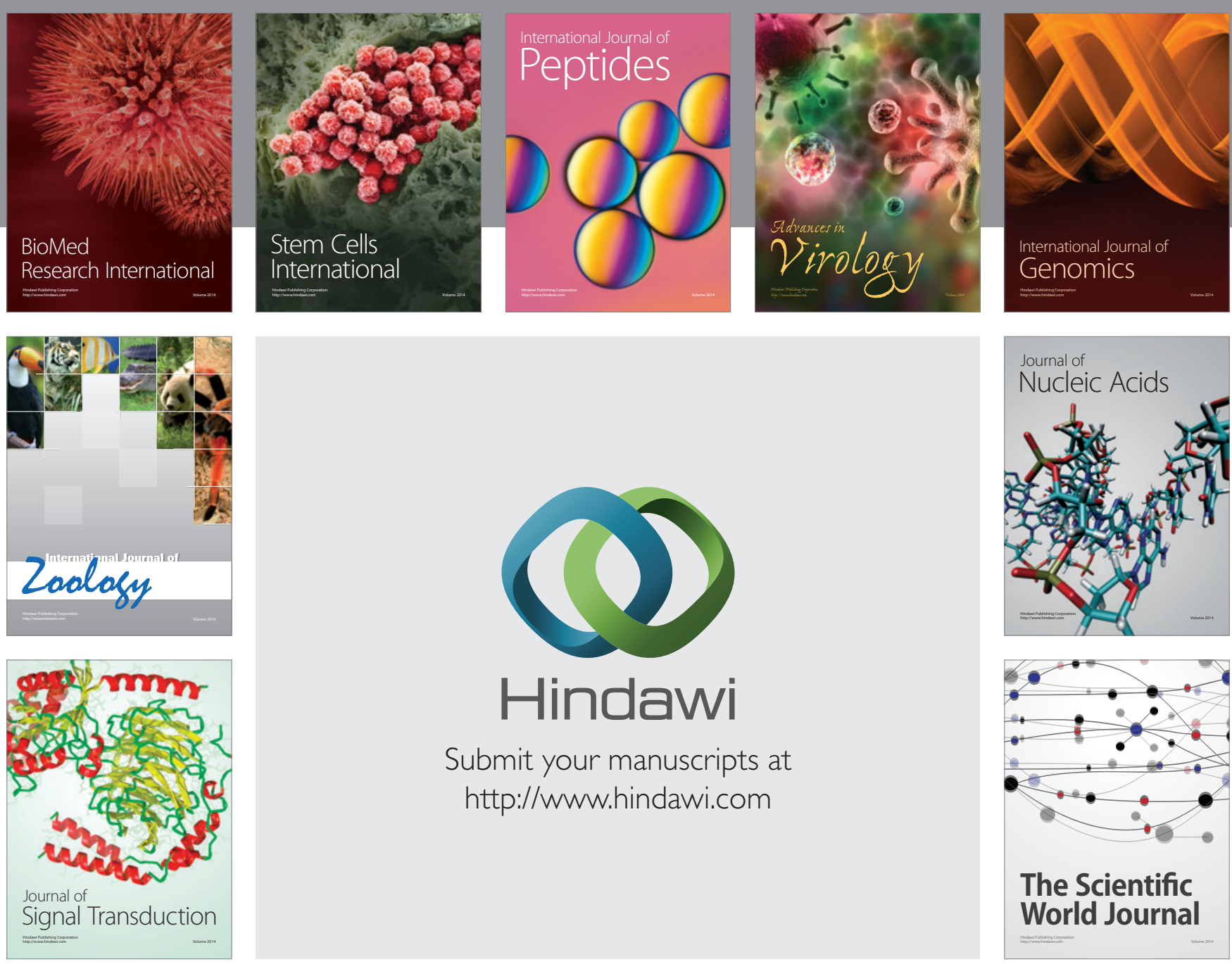

Submit your manuscripts at

http://www.hindawi.com
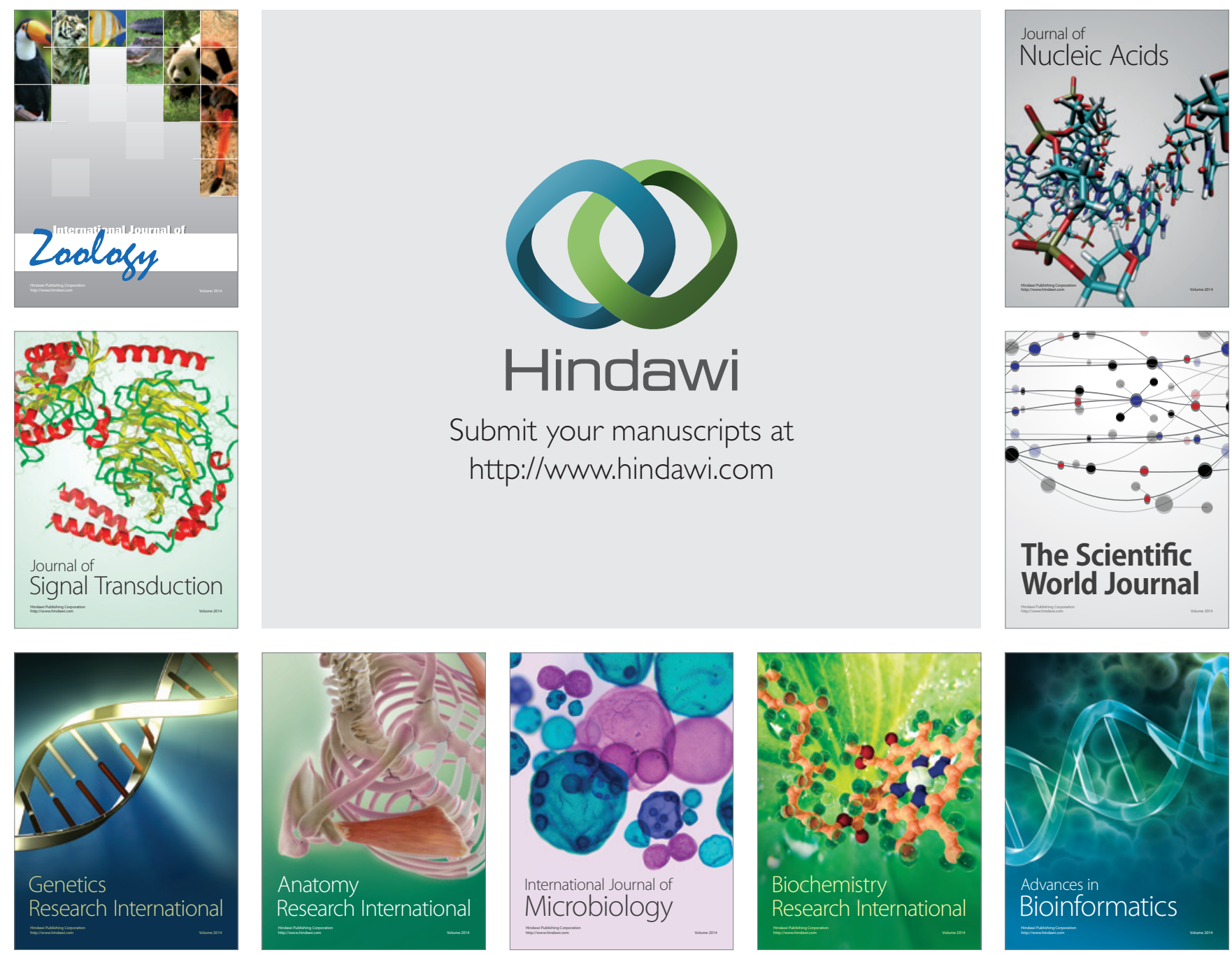

The Scientific World Journal
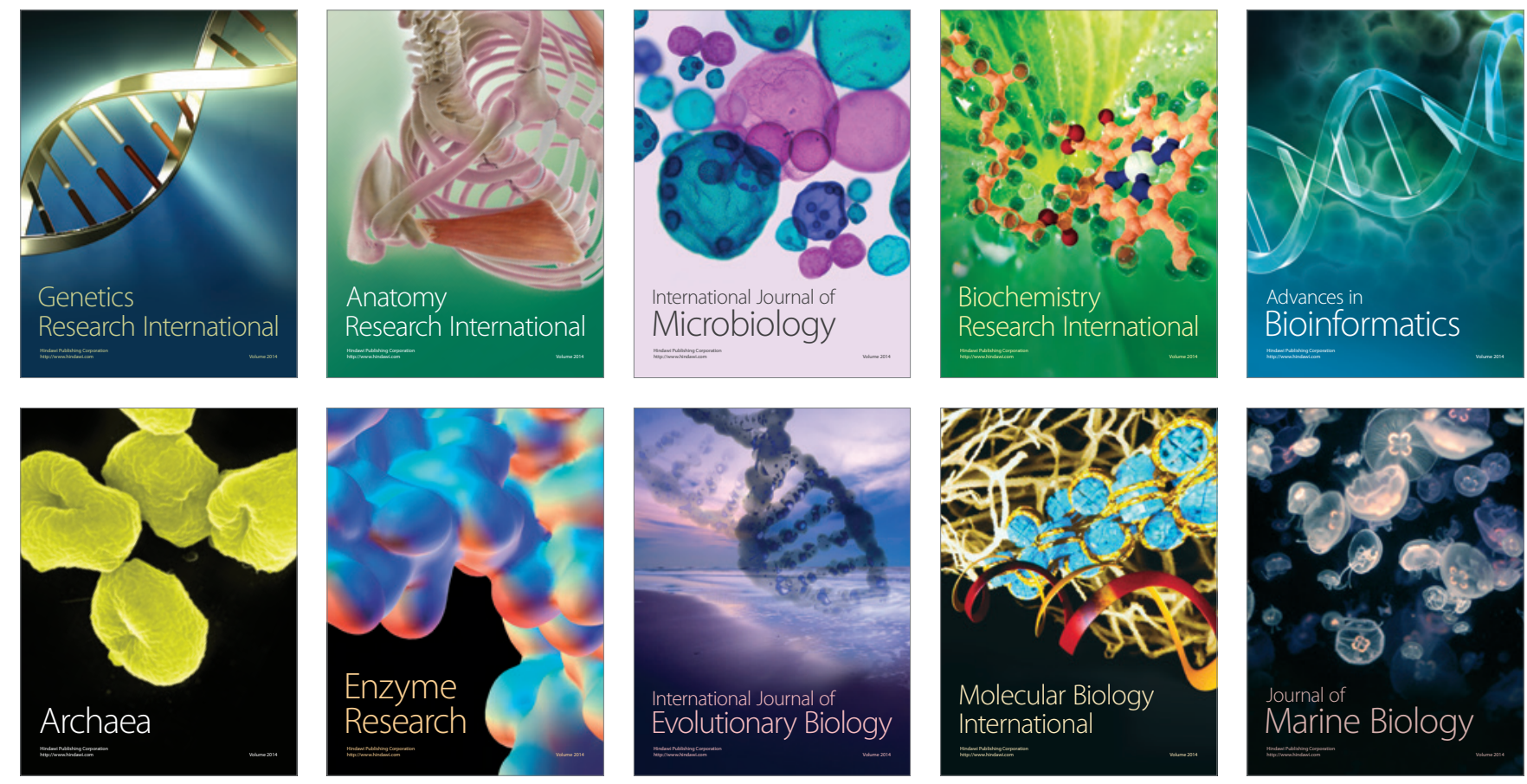